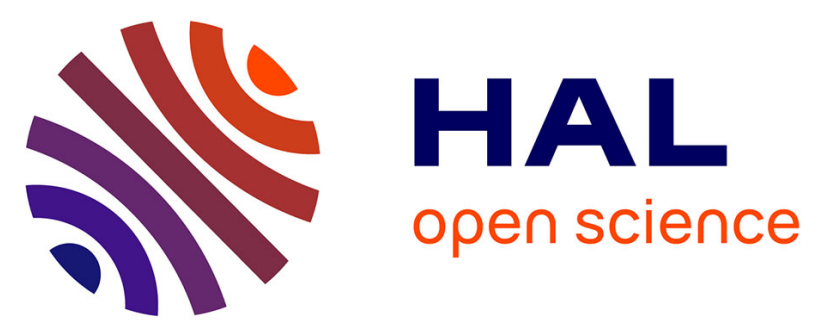

\title{
A Simple Isomerization of the Purine Scaffold of a Kinase Inhibitor, Roscovitine, Affords a Four- to Seven-Fold Enhancement of Its Affinity for Four CDKs. Could This Be Traced Back to Conjugation-Induced Stiffenings/Loosenings of Rotational Barriers?
}

Krystel El Hage, Jean-Philip Piquemal, Nassima Oumata, Laurent Meijer, Hervé Galons, Nohad Gresh

\section{- To cite this version:}

Krystel El Hage, Jean-Philip Piquemal, Nassima Oumata, Laurent Meijer, Hervé Galons, et al.. A Simple Isomerization of the Purine Scaffold of a Kinase Inhibitor, Roscovitine, Affords a Four- to Seven-Fold Enhancement of Its Affinity for Four CDKs. Could This Be Traced Back to ConjugationInduced Stiffenings/Loosenings of Rotational Barriers?. ACS Omega, 2017, 2 (7), pp.3467-3474. 10.1021/acsomega.7b00471 . hal-02126840

\author{
HAL Id: hal-02126840 \\ https://hal.science/hal-02126840
}

Submitted on 10 Nov 2021

HAL is a multi-disciplinary open access archive for the deposit and dissemination of scientific research documents, whether they are published or not. The documents may come from teaching and research institutions in France or abroad, or from public or private research centers.
L'archive ouverte pluridisciplinaire HAL, est destinée au dépôt et à la diffusion de documents scientifiques de niveau recherche, publiés ou non, émanant des établissements d'enseignement et de recherche français ou étrangers, des laboratoires publics ou privés. 


\title{
A Simple Isomerization of the Purine Scaffold of a Kinase Inhibitor, Roscovitine, Affords a Four- to Seven-Fold Enhancement of Its Affinity for Four CDKs. Could This Be Traced Back to Conjugation- Induced Stiffenings/Loosenings of Rotational Barriers?
}

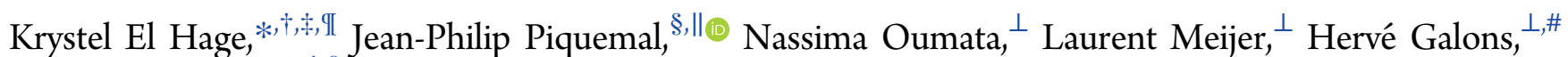
and Nohad Gresh*, $\dagger, \S$

${ }^{\dagger}$ Chemistry and Biology Nucleo(s)tides and Immunology for Therapy (CBNIT), UMR 8601 CNRS, UFR Biomédicale, Paris 75006, France

${ }^{\ddagger}$ Centre d'Analyses et de Recherche, UR EGFEM, LSIM, Faculté des Sciences, Saint Joseph University of Beirut, B.P. 11-514 Riad El Solh, Beirut 1107 2050, Lebanon

${ }^{\S}$ Laboratoire de Chimie Théorique, Sorbonne Universités, UPMC, UMR7616 CNRS, Paris 75005, France

"Department of Biomedical Engineering, The University of Texas at Austin, Austin, Texas 78712, United States

${ }^{\perp}$ ManRos Therapeutics, Hôtel de Recherche, Centre de Perharidy, Roscoff 29680, France

${ }^{\#}$ Unité de Technologies Chimiques et Biologiques pour la Santé, Université Paris Descartes UMR-S 1022 Inserm, 4 avenue de l'Observatoire, Paris 75006, France

Supporting Information

ABSTRACT: Roscovitine is an antitumor purine inhibitor of cyclin-dependent kinase CDK5, for which it displays submicromolar affinity. It reached phase IIb clinical trials in 2007. The search for analogues with improved kinase affinities led recently to an isomer, finisterine, having a nearly 10 -fold greater affinity for both CDK5 and CDK9. It solely differs by the displacement of one nitrogen atom in the purine ring, from position 6 to position 9. This has no incidence on the intermolecular interaction of either drug with the neighboring sites that anchor the ring in the recognition site. Quantum chemistry calculations combined with conformational and topological analyses of the impact of the purine ring isomerization of roscovitine and finisterine on its conformational stability show that the modified electronic conjugation, on the other hand, results in a stiffening of the rotational barrier around the extracyclic $\mathrm{C}-\mathrm{NH}$ bond of finisterine, vicinal to $\mathrm{N} 9$, and to which an aryl ring is connected, along with a loosening of the barrier around an extracyclic $\mathrm{C} 6-\mathrm{C}$ bond connecting to a shorter, hydrophobic arm. The first effect is proposed to lead to a lesser hydration entropy of solvation in the case of finisterine, thus to a facilitated desolvation term in the overall energy balances.

\section{INTRODUCTION}

Roscovitine (Figure 1A, left compound) is a submicromolar inhibitor of cyclin-dependent kinases $(\mathrm{CDKs})^{1}$ (reviews: refs 2-4), which has been in clinical trials against various cancers. $^{5-8}$ It has been evaluated against a large variety of other diseases, such as stroke, ${ }^{9}$ Parkinson's disease, ${ }^{10}$ Alzheimer's disease (L.H. Tsai, personal communication), cranial trauma, ${ }^{11}$ pain signaling, ${ }^{12}$ various viral infections, ${ }^{13}$ polycystic kidney disease, ${ }^{14,15}$ glomerulonephritis, ${ }^{16-19}$ glaucoma, ${ }^{20,21}$ Lambert-Eaton syndrome, ${ }^{22,23}$ deafness, ${ }^{24}$ Timothy syndrome, ${ }^{25,26}$ fibrosis, ${ }^{27}$ Cushing disease, ${ }^{28,29}$ and diabetes. ${ }^{30}$ Roscovitine is now reaching clinical trials against Cushing disease, $^{31}$ rheumatoid arthritis, ${ }^{32}$ and cystic fibrosis. ${ }^{33,34}$ The search for even more efficient inhibitors replaced the benzyl arm at the $\mathrm{C} 1$ position by aryl-pyridine (1, Figure 1A, middle
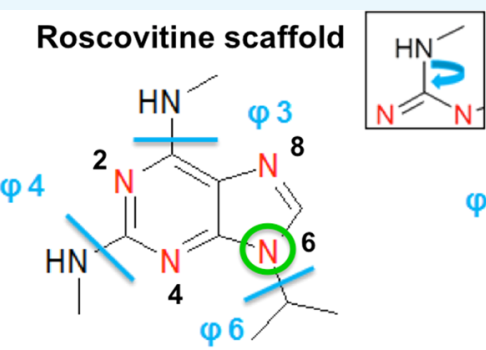

Finisterine scaffold

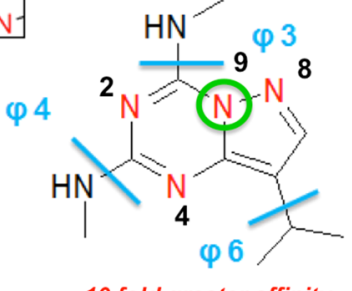

10 fold greater affinity compound) and, similarly, to an aryl-pyridine analogue of roscovitine isomer of $\mathbf{1}$ (2, Figure 1A, right compound, finisterine), has an order of magnitude smaller $\mathrm{IC}_{50}$ than $\mathbf{1}^{35,36}$ for the inhibition of CDK5 and CDK9. Yet, the sole change is a displacement in the purine ring of a nitrogen atom from position 6 to position 9 and its concomitant replacement at 6 by a $\mathrm{C}$ atom (Figure 1A, green circles). The $\mathrm{X}$-ray structure of the CDK9-compound $\mathbf{1}$ (compound designated originally as CR8) complex ${ }^{37}$ shows that the sole polar interactions of the purine ring is the double $\mathrm{H}$-bond of its $\mathrm{N} 8$ and its $\mathrm{C1}$ connected $\mathrm{NH}$ group with the $\mathrm{NH}$ and $\mathrm{CO}$ of the Phe105

Received: April 18, 2017

Accepted: June 28, 2017

Published: July 12, 2017 
A
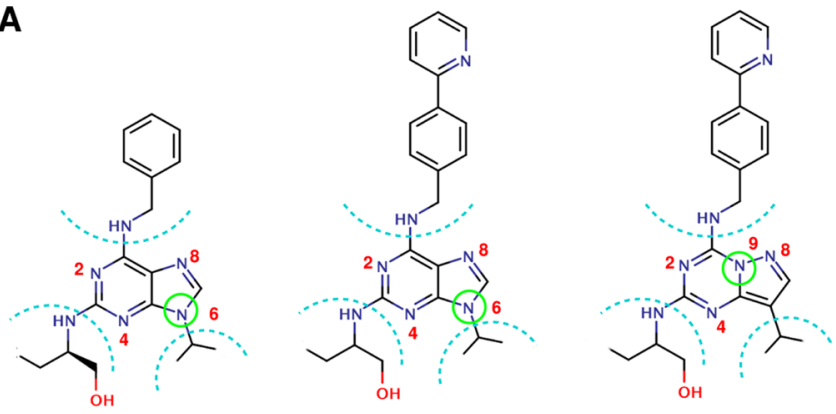

$\mathrm{IC}_{50}$ Roscovitine

Roscovitine derivative (1) Finisterine (2)

CDK1 0.33

CDK2 0.21

CDK5 0.28

CDK9 $\quad 0.23$

B
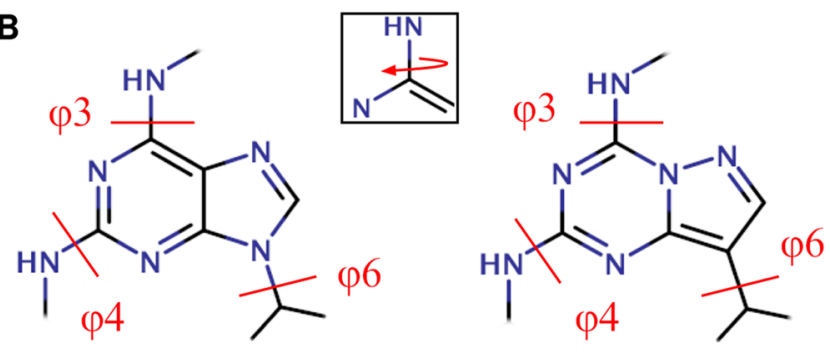

Figure 1. Roscovitine analogues. (A) Molecular structures of roscovitine (left compound), its aryl-pyridine derivatives (1, middle compound), and of the aryl-pyridine analogue of roscovitine isomer of 1 (2, right compound, finisterine). The displaced $\mathrm{N}$ atom is marked by a green circle. The inserted table gives the $\mathrm{IC}_{50}(\mu \mathrm{M})$ values for the inhibitions of four CDK kinases: CDK1, CDK2, CDK5, and CDK9. (B) Structures of the scaffold (purine ring) corresponding to compounds 1 and 2. The junctional bonds connecting the scaffold with the rest of the molecule are marked with a red bar and noted $\varphi 3$, $\varphi 4$, and $\varphi 6$ (depicting junctional bonds $\mathrm{C} 1-\mathrm{N}, \mathrm{C} 3-\mathrm{N}$, and N6/C6$\mathrm{C}$, respectively).

main-chain. Isomerization of the 6 and 9 positions leading to 2 is unlikely to impact the magnitude of such an interaction. All other interactions of the purine ring take place with hydrophobic residues. These involve Ile 25, Phe 103, and Phe 105 on one side of the plane and Leu 156 on the other side. Such interactions are insensitive to local electronic rearrangements of the ring. Should, then, the 10 -fold enhancement have another cause than actual differences of CDK5-ligand interaction energies?

If the ligand-CDK interaction energies were equal or closely comparable, a possible difference in the solvation energies of the two ligands could provide a ready explanation because a lesser solvation energy of $\mathbf{2}$ than $\mathbf{1}$ would favor it in the energy balances. Using the C-PCM method, ${ }^{38,39}$ we have thus compared the continuum solvation energies of the two rings. The purine ring of $\mathbf{2}$ has a lesser $\Delta G_{\text {solv }}$ than that of $\mathbf{1}$, namely $-13.9 \mathrm{kcal} / \mathrm{mol}$ as compared to -15.1 , consistent with the 1.4 $\mathrm{kcal} / \mathrm{mol}$ complexation free energy difference related to the 10fold $\mathrm{IC}_{50}$ decrease. It could, however, be questioned whether a $\Delta G_{\text {solv }}$ difference computed for the sole purine rings is accountable for the true difference of the solvation energies of $\mathbf{1}$ and $\mathbf{2}$ in their entireties. In these, the three substituents at positions 1,3 , and 6 could to a large extent shield the purine ring from the solvent, thus reducing this difference.
Comparisons of the free energies of solvation of $\mathbf{1}$ and $\mathbf{2}$ in explicit water, by either molecular dynamics (MD) or MonteCarlo, can therefore be necessary. As a prerequisite for such simulations by quantum chemistry (QC)-based force-field approaches, ${ }^{40,41}$ it is necessary to first calibrate the rotation barriers around each of the three torsion angles by QC (Figure 1B). We report below the results of conformational QC calculations. These illustrate the impact of varying the purine ring conjugation on conformational flexibilities, and this in turn should impact the comparative energy balances.

\section{RESULTS AND DISCUSSION}

We denote by $\varphi 3, \varphi 4$, and $\varphi 6$ the torsion angles around the bond connecting to the aryl, ethanolamine, and isopropyl substituents, respectively (see Figure 1B). Eighteen $15^{\circ}$ stepwise rotations were done, and the intramolecular energies were computed at the DFT level using the B97-D functional ${ }^{42}$ and the aug-cc-pVTZ basis set. ${ }^{43,44}$ The calculations were done with the G09 software. ${ }^{45}$ Results at both the Hartree-Fock (HF) and the Møller-Plesset (MP2) levels are given as Supporting Information S1 and S2, respectively. The curves for the relative conformation energies, $\delta E_{\text {conf }}$, for rotations around $\varphi 3, \varphi 4$, and $\varphi 6$ are plotted in Figure $2 \mathrm{~A}-\mathrm{C}$. The blue and the red curves correspond to $\mathbf{1}$ and $\mathbf{2}$, respectively.

Although for $\varphi 3$ both 1 and 2 have superimposable curves over the $0-135$ and $255-345^{\circ}$ ranges, there are stark differences in the $150-240^{\circ}$ range. 1 has significantly lower $\delta E_{\text {conf }}$ values, down to $4 \mathrm{kcal} / \mathrm{mol}$ at $180^{\circ}$, than 2 , where it is never smaller than $12 \mathrm{kcal} / \mathrm{mol}$. In fact the highest point for 2 in this range, at $195^{\circ}$ (the purine ring $\delta E_{\text {conf }}=20 \mathrm{kcal} / \mathrm{mol}$ ), has as counterpart the corresponding lowest point for $\mathbf{1}\left(\delta E_{\text {conf }}=4\right.$ $\mathrm{kcal} / \mathrm{mol})$. For $\varphi 4$, on the other hand, both 1 and 2 have virtually superimposable curves over the whole angular ranges. In marked contrast, for $\varphi 6$ it is now 2 that has the smallest $\delta E_{\text {conf }}$ values. These occur on both sides of the degenerate minima at 0 and $180^{\circ}$.

The similar conformational behaviors around $\varphi 4$ are clearly due to the presence of identical atoms ( 22 and $\mathrm{N} 4$ ) ortho to the $\mathrm{C} 3-\mathrm{N}$ torsional bond. Regarding $\varphi 6$, it is noted that the torsional bonds are a $\mathrm{N}-\mathrm{C}$ one for $\mathbf{1}$ and a $\mathrm{C}-\mathrm{C}$ one for 2 : thus a straightforward argument would be that an sp lone-pair on a nitrogen as in $\mathbf{1}$ confers greater rigidity than an sp lonepair on a carbon, as in $\mathbf{2}$. Could this be borne out by electronic density analyses? The case of $\varphi 3$ is more involved because the torsional bond is $\mathrm{C} 1-\mathrm{N}$ for both $\mathbf{1}$ and 2 . In contrast, in 1, C1 has in ortho one $\mathrm{N}$ atom, $\mathrm{N} 2$, and one $\mathrm{C}$ atom, $\mathrm{C} 9$, whereas in $2 \mathrm{C} 1$ has as ortho atoms $\mathrm{N} 2$ and $\mathrm{N} 9$.

These considerations led us to resort to two types of topological analyses: electron localization function (ELF) ${ }^{46-48}$ and noncovalent interactions (NCIs). ${ }^{49,50}$ Regarding bond $\mathrm{C} 1-\mathrm{NH}$ around which the $\varphi 3$ torsions are performed, Figure $3 \mathrm{~A}, \mathrm{~B}$ shows two green surfaces around $\mathrm{N} 2$ and N8, which translate their involvement in attractive interactions. However, concerning $\mathbf{2}$ (Figure 3B), a much more intense green surface is observed around N8 than is the case with 1 . This clearly indicates a stronger $\mathrm{H}$-bond interaction between the exacyclic $\mathrm{NH}$ group and the in-plane sp doublet of N8. It occurs at $\varphi 3=$ 0 , which is the global energy minimum for both 1 and 2 . N9 in 2 cannot partake to the binding since it has no sp doublet. It could only reinforce this $\mathrm{H}$-bond interaction through conjugation. This is borne out by ELF analyses, which show different electronic localizations on $\mathrm{N} 8, \mathrm{C} 9 / \mathrm{N} 9$, and on the extracyclic $\mathrm{NH}$ group. In 2, an electronic population of 2.11 


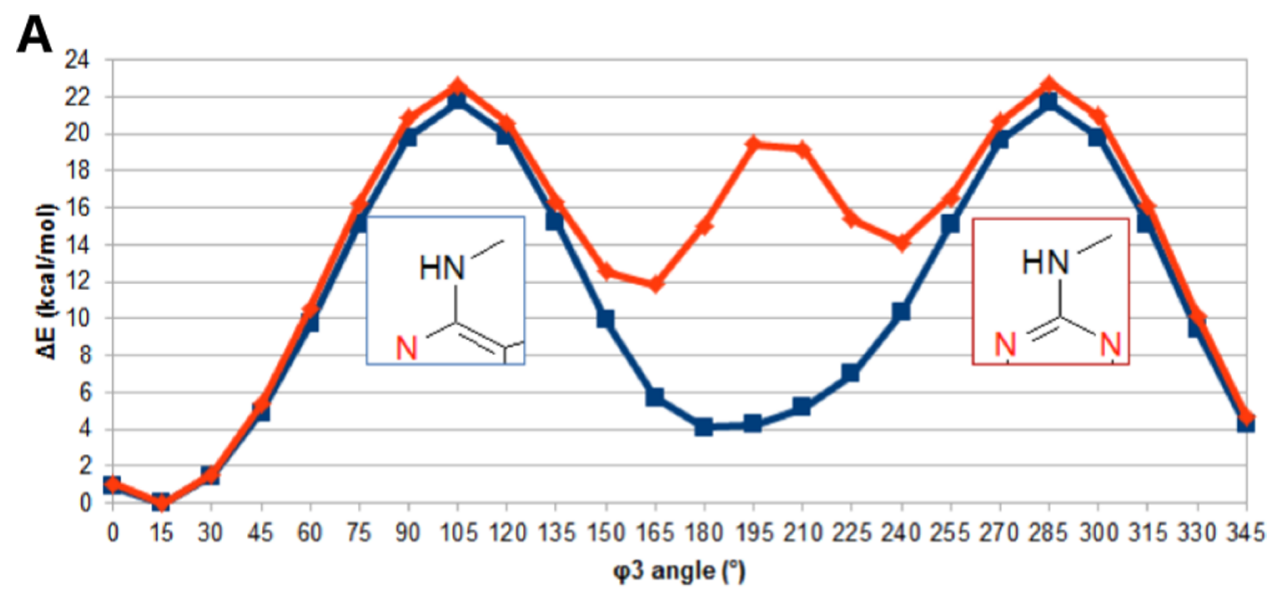

B
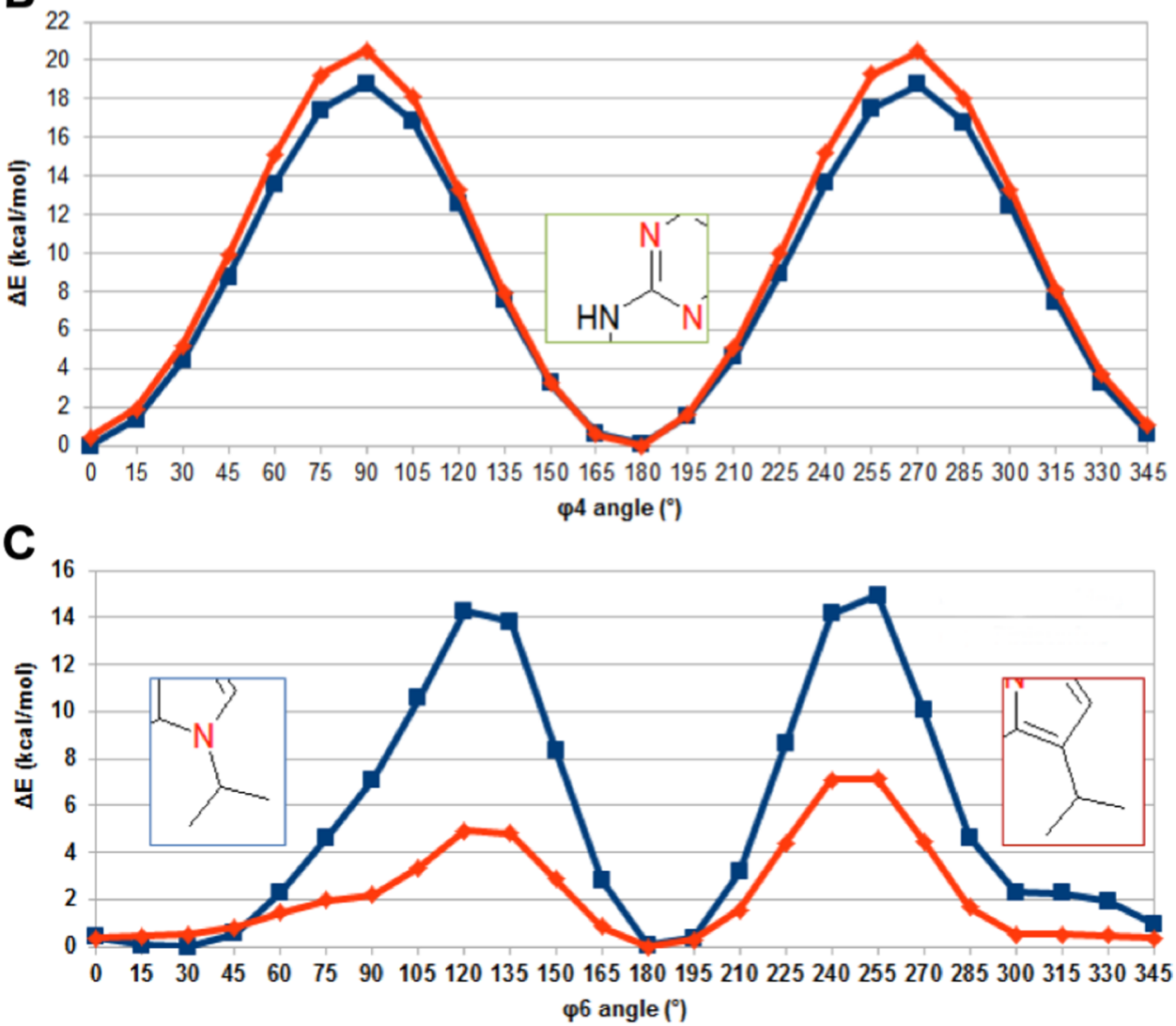

Figure 2. Conformational energy variations upon rotations around junctional bonds $\mathrm{C} 1-\mathrm{N}(\varphi 3)(\mathrm{A}), \mathrm{C} 3-\mathrm{N}(\varphi 4)(\mathrm{B})$, and N6/C6-C $(\varphi 6)(\mathrm{C})$. The curves for 1 (roscovitine derivative) and $\mathbf{2}$ (finisterine) are in blue and red, respectively.

electrons is located in a volume of $17.7 \mathrm{au}^{3}$, hence a density of 0.12 , whereas in 1 , an electronic population of 2.65 electrons is located in a volume of $29.6 \mathrm{au}^{3}$, hence a smaller density of 0.09 . The greater compaction of the N8 electron density in $\mathbf{2}$ than in $\mathbf{1}$ is consistent with the NCI analyses, which are indicative of stronger interactions involving $\mathrm{N} 2$ in the case of 2 . It is also worth noting that $\mathrm{N} 9$ has in $\mathbf{2}$ greater compaction than C9 in $\mathbf{1}$, namely 7.57 electrons in a volume of $79 \mathrm{au}^{3}$ for N9, as compared to 5.82 electrons in a volume of $109.3 \mathrm{au}^{3}$ for C9. This could also contribute to reinforcing the relative rigidity for $\varphi 3$ rotations in $\mathbf{2}$ compared to that in $\mathbf{1}$. Regarding the torsions around $\varphi 4$, the NCI and ELF analyses concur again, as shown in Supporting information S3. The NCI surfaces close to N2 have the same amplitudes in $\mathbf{1}$ and 2, whereas the ELF densities around bonds $\mathrm{N} 2-\mathrm{C} 3, \mathrm{C} 3-\mathrm{N}$, and $\mathrm{N}-\mathrm{C}$ are virtually identical, namely 5.84 electrons in a volume of $79.5 \mathrm{au}^{3}$ for 1 and 5.84 electrons in a volume of 79.3 for $\mathbf{2}$. This is fully consistent with the similar $\delta E_{\text {conf }}$ variation amplitudes in both ligands. Regarding the $\varphi 6$ variations, NCI and ELF show contrasting contours around N6 in 1 and C6 in 2. There are two green surfaces on both sides of N6 in 1, in the vicinities of N4 and C7 (Figure 4A). Such attractions should confer rigidity for rotations around $\varphi 6$. By contrast, the green surface around $\mathrm{N} 4$ has in $\mathbf{2}$ a much smaller extension, and there is virtually no contour around C7 (Figure 4B). Such much smaller planar interactions of the isopropyl with the purine ring should contribute to the much greater lability for $\varphi 6$ rotations in 2 . These considerations are borne out by the ELF analyses, which show the presence of a much denser electron distribution around N6 in 1 (Figure 4C) than around C6 in 2 (Figure 4D). 
A
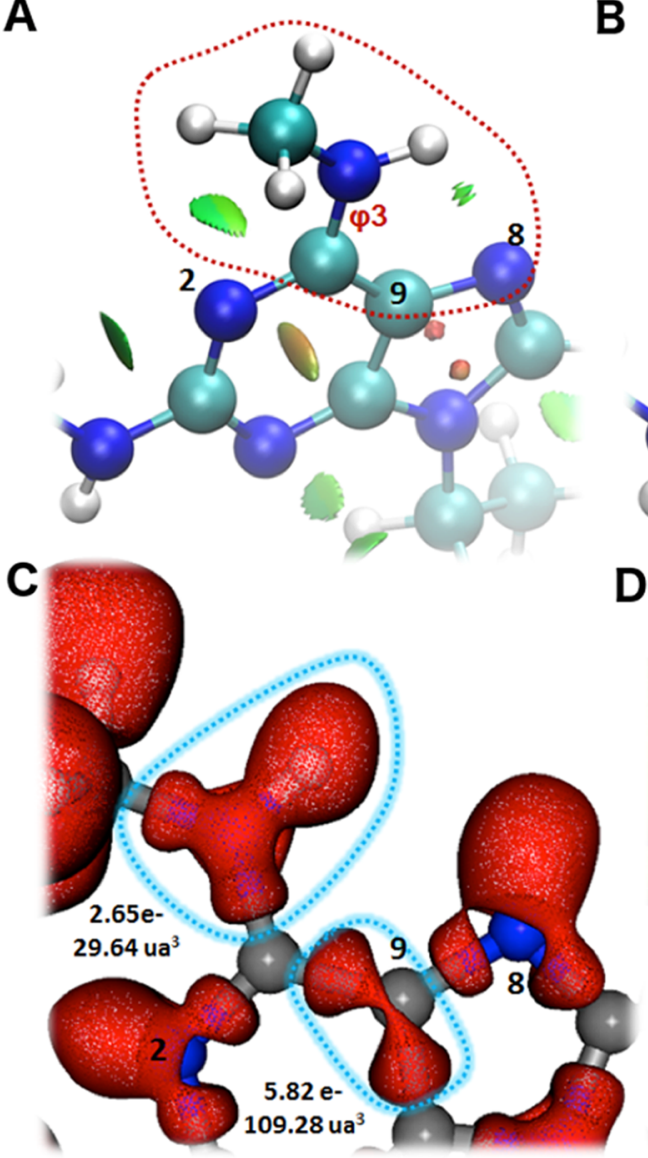

B

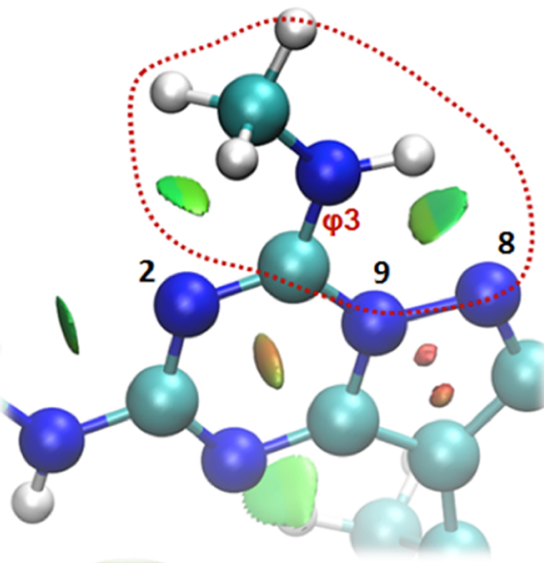

D

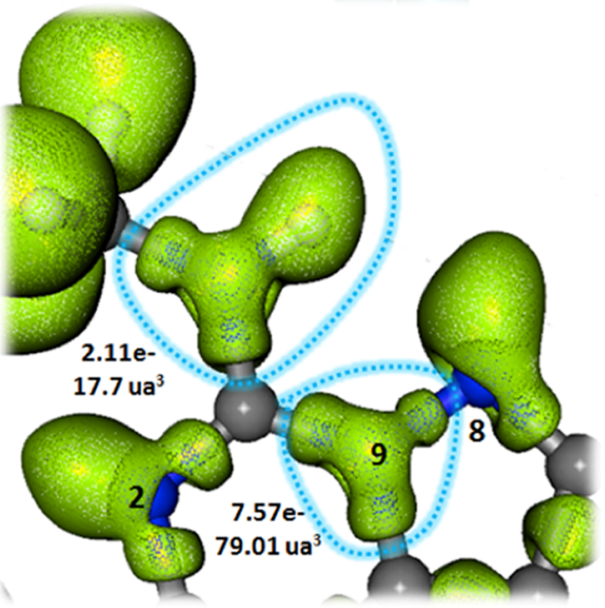

Figure 3. NCI surfaces in the vicinity of the $\mathrm{C} 1-\mathrm{N}(\varphi 3)$ bonds for 1 (roscovitine derivative) (A) and 2 (finisterine) (B). ELF contours in the vicinity of the $\mathrm{C} 1-\mathrm{N}(\varphi 3)$ bonds for 1 (C) and 2 (D).

Thus in $\mathbf{1}$ a total population of 6.77 electrons is found in a volume of $61.1 \mathrm{au}^{3}$ at the periphery of the C5-N6, N6-C7, and N6-C (isopropyl) bonds. In 2, the total electron population in the three basins around $\mathrm{C6}$ is much more diffuse, with 7.89 electrons in a volume of $137.2 \mathrm{au}^{3}$, and the three basins are disconnected.

What could be the impact, for the comparative binding affinities to CDK of 1 and 2, of their differing flexibilities for rotations around bonds $\mathrm{C} 1-\mathrm{N}(\varphi 3)$ and N6/C6-C $(\varphi 6)$ ? Rotations around $\mathrm{C} 1-\mathrm{N}$ govern the conformation of the bicyclic aryl-pyridine ring. A greater lability in $\mathbf{1}$ compared to that of $\mathbf{2}$ will result in a larger entropy component, $T \Delta S$ : this concerns both its free energy of solvation before complexation and its complexation energy to the CDK receptor. Regarding $\Delta G_{\text {solv }}$, the extended length and the partly polar nature of the aryl-pyridyl arm are expected to thermalize more the water layers around it with 1 than with 2 , hence a larger $T \Delta S_{\text {solv }}$. Using QC-derived force-fields, we plan to perform $\mathrm{MD}$ simulation of the solvation energies of $\mathbf{1}$ and $\mathbf{2}$, varying the temperature around $300 \mathrm{~K}$ to resolve $\Delta G_{\text {solv }}$ into its separate $\Delta H_{\text {solv }}$ and $T \Delta S_{\text {solv }}$ components. This should quantify the $T \Delta S_{\text {solv }}$ difference between $\mathbf{1}$ and 2 . It will then be necessary to evaluate the extent to which this difference could be recovered by a correspondingly larger vibration entropy upon binding to the CDK cavity, itself depending upon the size of the arylpyridyl binding pocket. We thus plan to perform MD studies on the binding of $\mathbf{1}$ and 2 to CDK targets, as well as a quantitative evaluation of the vibration entropy, $T \Delta S_{\text {vib, }}$ contribution to $\Delta G$. By contrast, the larger lability for rotations around the N6/C6-C bonds for 2 than for 1 should confer greater $T \Delta S_{\text {solv }}$ and smaller $T \Delta S_{\text {vib }}$ to 2 . However, both effects should be lesser than in the case of the $\mathrm{C} 1-\mathrm{N}$ rotation, owing to the smaller volume of the isopropyl substituent at 6 than of the aryl-pyridine at 1 , as well as its more hydrophobic nature. Alternatively, the increased flexibility for rotations around $\varphi 6$ could favor $\mathbf{2}$ over $\mathbf{1}$ in their CDK5 complexes. This is because the two equivalent $-\mathrm{CH}_{3}$ groups of the shorter isopropyl substituent could interact by van der Waals interactions with the Phe 103 and Phe 105 side chains in a much larger manifold of conformations in the case of 2 , and such a stabilization would, again, stem from entropy.

While this article was in preparation, a paper by Nekardová appeared, ${ }^{51}$ which compared the scoring functions of several roscovitine derivatives with different heterocycle scaffolds, earlier reported by this group. ${ }^{52}$ Among these compounds, a derivative with the same scaffold as finisterine (denoted as A3) but with the same side chains as roscovitine was endowed with a 10-fold larger inhibitory potency than roscovitine. This finding is fully consistent with ours, the compounds reported by Nekardova et al. ${ }^{51}$ differing by an amino-benzyl side chain at position 1 rather than by an amino-benzyl-pyridine side chain as in the present study. This 10 -fold larger affinity could be successfully accounted for by a correspondingly $1.5 \mathrm{kcal} / \mathrm{mol}$ larger magnitude of the scoring function of A3 than roscovitine. Such scoring functions were derived by energy optimizations of an ab initio quantum chemistry/semiempirical quantum chemistry (QC/SQC) of the ligand-protein complexes in the presence of continuum energy solvation. Energy balances 

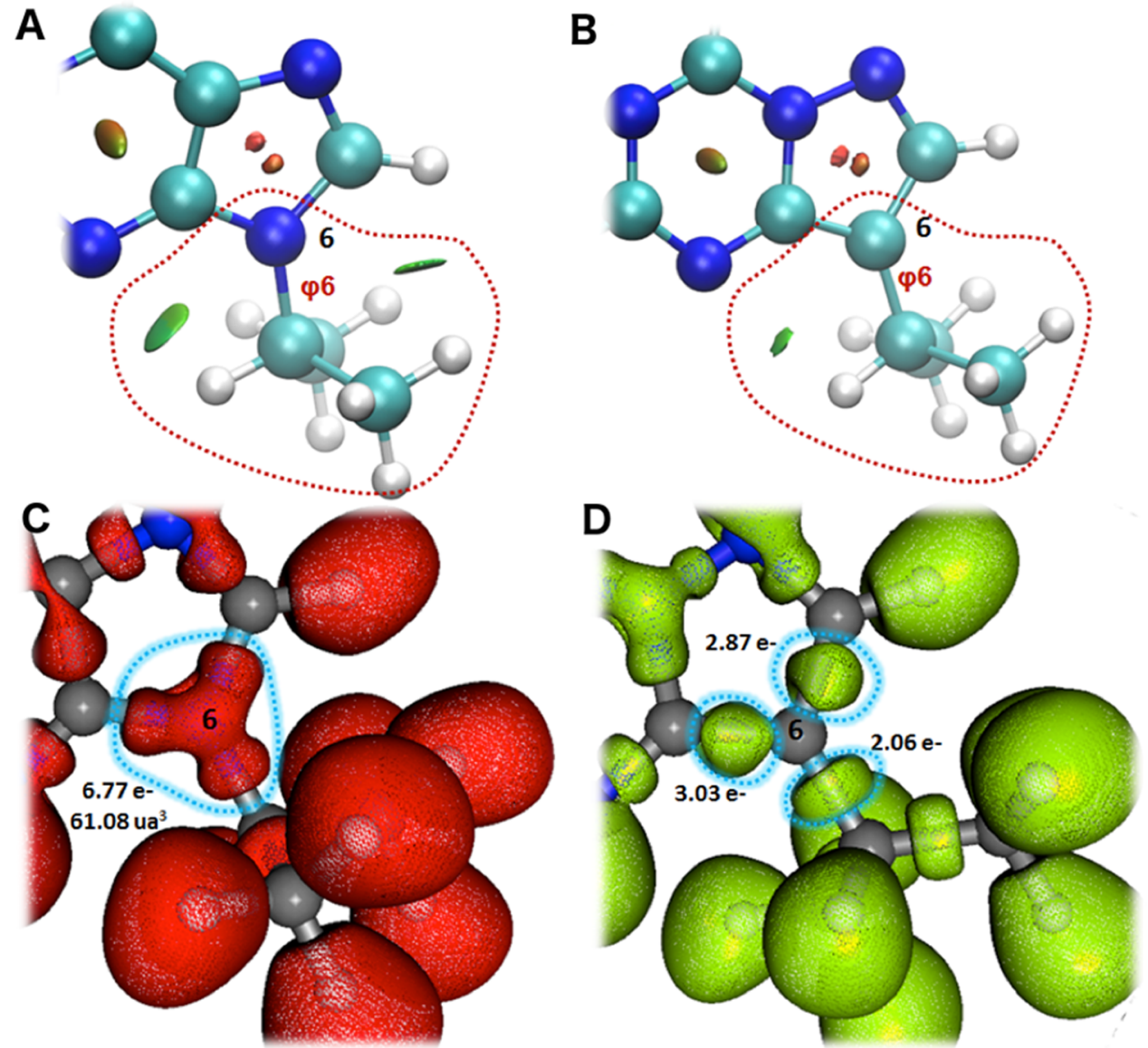

Figure 4. NCI surfaces in the vicinity of the N6/C6-C $(\varphi 6)$ bonds for 1 (roscovitine derivative) (A) and 2 (finisterine) (B). ELF contours in the vicinity of the N6/C6-C $(\varphi 6)$ bonds for 1 (C) and 2 (D).

were done by subtracting the conformational energies of the ligands optimized in the presence of continuum solvation. Entropy effects were computed by vibrational analysis. Dynamic effects were taken into account solely in the context of the empirical AMBER force-field, to generate ligand conformations suitable for subsequent docking and energy optimization. The details of the energy balances were not provided. In light of the present analysis, it would be instructive to trace back the weight of differential solvation free energies of roscovitine and A3 on the energy balances. The present calculations indicate that this term could be critical. The results by Nekardová et al. ${ }^{51}$ and the need stressed in the present article to quantify the roles of ligand-kinase versus ligand desolvation are an incentive for a subsequent and major step forward, namely, free energy calculations with polarizable MD.

\section{CONCLUSIONS AND PERSPECTIVES}

An aryl-pyridine derivative of roscovitine, a drug presently undergoing clinical trials, has a submicromolar CDK-binding potency. A novel derivative, finisterine, differs from it by a simple isomerization of the purine ring, $\mathrm{C} 9$ and $\mathrm{N} 6$ being replaced by $\mathrm{N} 9$ and $\mathrm{C} 6$. This novel compound, 2, has a near ten-fold higher CDK-binding affinity than the parent compound, 1. This could not result from a more favorable enthalpy-wise intermolecular interaction energy to CDK. As a first step toward understanding the reasons for such a preference, we investigated the conformational energies of 1 and 2 upon performing rotations around the three bonds connecting the purine ring to its three substituents. The essential finding from this study is that $\mathbf{1}$ and $\mathbf{2}$ have major differences regarding their conformational flexibilities around two bonds: $\mathrm{C} 1-\mathrm{N}$ governing the conformation of the aryl pyridine ring, and N6-C governing the conformation of the isopopryl substituent. $\mathbf{2}$ has a much lesser conformation lability than 1 regarding the first torsional bond, and, conversely, a much greater lability regarding the second. These results were consistent with NCI and ELF analyses, showing that more rigid rotation barriers corresponded to both more extended NCI surfaces and more compact ELF densities. Rigidity around the $\mathrm{C} 1-\mathrm{N}$ bond could be more critical to the overall energy balances, as it would reduce the loss of conformational entropy of the aryl-pyridine arm upon passing from the water solution to the more confined CDK-binding pocket, as occurring with 2 . The corresponding entropy loss regarding the isopropyl arm would be significantly smaller on account of its smaller volume and absence of hydrophilicity. Work is planned for $\mathrm{MD}$ simulations of $\mathbf{1}$ and $\mathbf{2}$ in both water and in their CDK complexes, to unravel the $T \Delta S$ contribution to $\Delta G$ in both cases, and will be reported in due course.

The differences in the conformational behaviors of 1 and 2 regarding $\varphi 3$ and $\varphi 6$ torsion angles are very meaningful and should justify the fact that the present study focuses on these sole two compounds. These also imply that a preexisting bias should favor $\mathbf{2}$ over $\mathbf{1}$ and should to a large extent prevail over the fine details of the CDK-binding site. This is indeed observed in Figure 1A, bearing on four CDKs, with affinity ratios in the $3.5-7$ range. 
We recently showed that electron substitutions in halobenzene derivatives, upon modifying electron density by conjugation, impacted both distributed multipoles and distributed polarizabilities used in polarizable molecular mechanics (PMM) approaches. This resulted in changes in the magnitude of both PMM electrostatic and polarization contributions, fully supported by their Coulomb and exchangerepulsion counterparts from energy decomposition analyses. ${ }^{53}$ The present study shows that isomerization in a conjugated ring can strongly decrease torsional flexibility around bonds connecting to substituents, due to localized increases of the electron density. This should in turn affect configurational entropy in water solution and vibrational entropy in the CDK complex. In a broader context, it could constitute a new and possibly uncharted avenue to affect binding affinities; thus, modulating conformational flexibility could be done by selected isomerizations and also possibly by some electron-donating substituents at appropriate locations with respect to the junction bond. Such effects could be quantified by preliminary NCI, ELF, and QC conformational analyses. The derivatives retained would subsequently lend themselves to PMM MD simulations of their solvation in water and of their complexes with the receptor. There does not seem to exist any precedent for such an approach.

\section{ASSOCIATED CONTENT}

\section{S Supporting Information}

The Supporting Information is available free of charge on the ACS Publications website at DOI: 10.1021/acsomega.7b00471.

Detailed method section; S1A-C: HF conformational energy variations upon rotations around junctional bonds $\mathrm{C} 1-\mathrm{N}(\varphi 3), \mathrm{C} 3-\mathrm{N}(\varphi 4)$, and N6/C6-C $(\varphi 6)$. The curves for 1 (roscovitine derivative) and 2 (finisterine) are in blue and red, respectively; S2A-C: MP2 conformational energy variations upon rotations around junctional bonds $\mathrm{C} 1-\mathrm{N}(\varphi 3), \mathrm{C} 3-\mathrm{N}(\varphi 4)$, and $\mathrm{N} 6 /$ C6-C $(\varphi 6)$. The curves for 1 (roscovitine derivative) and 2 (finisterine) are in blue and red, respectively; S3A-D: NCI surfaces in the vicinity of the C3-N $(\varphi 4)$ bonds for 1 (roscovitine derivative) (A) and 2 (finisterine) (B). ELF contours in the vicinity of the C3-N ( $\varphi 4)$ bonds for 1 (C) and 2 (D) (PDF)

\section{AUTHOR INFORMATION}

\section{Corresponding Authors}

*E-mail: krystel.elhage@unibas.ch (K.E.-H.).

*E-mail: gresh@lct.jussieu.fr (N.G.).

ORCID

Jean-Philip Piquemal: 0000-0001-6615-9426

Nohad Gresh: 0000-0001-7174-2907

\section{Present Address}

II (K.E.-H.) Department of Chemistry, University of Basel, 4056 Basel, Switzerland.

\section{Notes}

The authors declare no competing financial interest.

\section{ACKNOWLEDGMENTS}

We sincerely thank the Association Philippe Jabre for funding the $\mathrm{PhD}$ research of Krystel El Hage. We wish to thank the Grand Equipement National de Calcul Intensif (GENCI): Institut du Développement et des Ressources en Informatique
Scientifique (IDRIS), Centre Informatique de l'Enseignement Supérieur (CINES), France, project No. x2009-075009), and the Centre de Ressources Informatiques de Haute Normandie (CRIHAN, Rouen, France), project 1998053. Some of the work was also supported by the "Association Vaincre la Mucoviscidose" (L.M.).

\section{REFERENCES}

(1) Meijer, L.; Borgne, A.; Mulner, O.; Chong, J. P. J.; Blow, J. J.; Inagaki, N.; Inagaki, M.; Delcros, J. G.; Moulinoux, J. P. Biochemical and cellular effects of roscovitine, a potent and selective inhibitor of the cyclin-dependent kinases cdc2, cdk2 and cdk5. Eur. J. Biochem. 1997, 243, 527-536.

(2) Meijer, L.; Raymond, E. Roscovitine and other purines as kinase inhibitors. From starfish oocytes to clinical trials. Acc. Chem. Res. 2003, $36,417-425$.

(3) Meijer, L.; Bettayeb, K.; Galons, H. Roscovitine (CYC202, Seliciclib). In Monographs on Enzyme Inhibitors, CDK Inhibitors and Their Potential as Anti-Tumor Agents; Yue, E., Smith, L. J., Eds.; CRC Press, 2006; Vol. 2, pp 187-226.

(4) Aldoss, I. T.; Tashi, T.; Ganti, A. K. Seliciclib in malignancies. Expert Opin. Invest. Drugs 2009, 18, 1957-1965.

(5) Benson, C.; White, J.; De Bono, J.; O’Donnell, A.; Raynaud, F.; Cruickshank, C.; McGrath, H.; Walton, M.; Workman, P.; Kaye, S.; Cassidy, J.; Gianella-Borradori, A.; Judson, I.; Twelves, C. A phase I trial of the selective oral cyclin-dependent kinase inhibitor seliciclib (CYC202; R-Roscovitine), administered twice daily for 7 days every 21 days. Br. J. Cancer 2007, 96, 29-37.

(6) Le Tourneau, C.; Faivre, S.; Laurence, V.; Delbaldo, C.; Vera, K.; Girre, V.; Chiao, J.; Armour, S.; Frame, S.; Green, S. R.; GianellaBorradori, A.; Diéras, V.; Raymond, E. Phase I evaluation of seliciclib (R-roscovitine), a novel oral cyclin-dependent kinase inhibitor, in patients with advanced malignancies. Eur. J. Cancer 2010, 46, 32433250.

(7) de la Motte, S.; Gianella-Borradori, A. Pharmacokinetic model of R-roscovitine and its metabolite in healthy male subjects. Int. J. Clin. Pharmacol. Ther. 2004, 42, 232-239.

(8) Hsieh, W. S.; Soo, R.; Peh, B. K.; Loh, T.; Dong, D.; Soh, D.; Wong, L. S.; Green, S.; Chiao, J.; Cui, C. Y.; Lai, Y. F.; Lee, S. C.; Mow, B.; Soong, R; Salto-Tellez, M.; Goh, B. C. Pharmacodynamic effects of seliciclib an orally administered cell cycle modulator in undifferentiated nasopharyngeal cancer. Clin. Cancer Res. 2009, 15, $1435-1442$

(9) Menn, B.; Bach, B.; Blevins, T. L.; Campbell, M.; Meijer, L.; Timsit, S. Delayed treatment with systemic (S)-roscovitine provides CDK5-mediated neuroprotection in animal stroke models. PLoS One 2010, 5, No. e12117.

(10) Chagniel, L.; Robitaille, C.; Lebel, M.; Cyr, M. Striatal inhibition of calpains prevents levodopa-induced neurochemical changes and abnormal involuntary movements in the hemiparkinsonian rat model. Neurobiol. Dis. 2012, 45, 645-655.

(11) Kabadi, S. V.; Stoica, B. A.; Byrnes, K. R.; Hanscom, M.; Loane, D. J.; Faden, A. I. Selective CDK inhibitor limits neuroinflammation and progressive neurodegeneration after brain trauma. J. Cereb. Blood Flow Metab. 2012, 32, 137-149.

(12) Utreras, E.; Futatsugi, A.; Pareek, T. K.; Kulkarni, A. B. Molecular roles of Cdk5 in pain signaling. Drug Discovery Today: Ther. Strategies 2009, 6, 105-111.

(13) Schang, L. M.; Bantly, A.; Knockaert, M.; Shaheen, F.; Meijer, L.; Malim, M. H.; Gray, N. S.; Schaffer, P. A. Pharmacological cyclindependent kinase inhibitors inhibit replication of wild-type and drugresistant strains of Herpes simplex virus and Human immunodeficiency virus type 1 by targeting cellular, not viral, proteins. J. Virol. 2002, 76, 7874-7882.

(14) Bukanov, N. O.; Smith, L. A.; Klinger, K. W.; Ledbetter, S. R.; Ibraghimov-Beskrovnaya, O. Long-lasting arrest of murine polycystic kidney disease with CDK inhibitor Roscovitine. Nature 2006, 444, 949-952. 
(15) Bukanov, N. O.; Moreno, S. E.; Natoli, T. A.; Rogers, K. A.; Smith, L. A.; Ledbetter, S. R.; Oumata, N.; Galons, H.; Meijer, L.; Ibraghimov-Beskrovnaya, O. CDK inhibitors R-roscovitine and S-CR8 effectively inhibit renal and hepatic cystogenesis in an orthologous model of ADPKD. Cell Cycle 2012, 11, 4040-4046.

(16) Pippin, J. W.; Qu, Q.; Meijer, L.; Shankland, S. J. Direct in vivo inhibition of the nuclear cell cycle cascade in experimental mesangial proliferative glomerulonephritis with Roscovitine, a novel cyclindependent kinase antagonist. J. Clin. Invest. 1997, 100, 2512-2520.

(17) Gherardi, D.; D’Agati, V.; Chu, T. H.; Barnett, A.; GianellaBorradori, A.; Gelman, I. H.; Nelson, P. J. Reversal of collapsing glomerulopathy in mice with the cyclin-dependent kinase inhibitor CYC202. J. Am. Soc. Nephrol. 2004, 15, 1212-1222.

(18) Milovanceva-Popovska, M.; Kunter, U.; Ostendorf, T.; Petermann, A.; Rong, S.; Eitner, F.; Kerjaschki, D.; Barnett, A.; Floege, J. R-roscovitine (CYC202) alleviates renal cell proliferation in nephritis without aggravating podocyte injury. Kidney Int. 2005, 67, 1362-1370.

(19) Zoja, C.; Casiraghi, F.; Conti, S.; Corna, D.; Rottoli, D.; Cavinato, R. A.; Remuzzi, G.; Benigni, A. Cyclin-dependent kinase inhibition limits glomerulonephritis and extends lifespan of mice with systemic lupus. Arthritis Rheum. 2007, 56, 1629-1637.

(20) Clinical Trials USA Safety and Intraocular Pressure (IOP)Lowering Efficacy of AL-39256 in Patients with Open-Angle Glaucoma or Ocular Hypertension, 2008. https://clinicaltrials.gov/ ct2/show/NCT00761709 (accessed May 25, 2017).

(21) Cholkar, K.; Trinh, H. M.; Pal, D.; Mitra, A. K. Discovery of novel inhibitors for the treatment of glaucoma. Expert Opin. Drug Discovery 2015, 10, 293-313.

(22) Liang, M.; Tarr, T. B.; Bravo-Altamirano, K.; Valdomir, G.; Rensch, G.; Swanson, L.; DeStefino, N. R.; Mazzarisi, C. M.; Olszewski, R. A.; Wilson, G. M.; Meriney, S. D.; Wipf, P. Synthesis and biological evaluation of a selective $\mathrm{N}$ - and $\mathrm{P} / \mathrm{Q}-\mathrm{Type}$ calcium channel agonist. ACS Med. Chem. Lett. 2012, 3, 985-990.

(23) Tarr, T. B.; Valdomir, G.; Liang, M.; Wipf, P.; Meriney, S. D. New calcium channel agonists as potential therapeutics in LambertEaton myasthenic syndrome and other neuromuscular diseases. Ann. N. Y. Acad. Sci. 2012, 1275, 85-91.

(24) Malgrange, B.; Knockaert, M.; Belachew, S.; Nguyen, L.; Moonen, G.; Meijer, L.; Lefebvre, P. P. The inhibition of cyclindependent kinases induces differentiation of supernumerary hair cells and Deiters' cells in the developing organ of Corti. FASEB J. 2003, 17, 2136-2138.

(25) Yazawa, M.; Hsueh, B.; Jia, X.; Pasca, A. M.; Bernstein, J. A.; Hallmayer, J.; Dolmetsch, R. E. Using induced pluripotent stem cells to investigate cardiac phenotypes in Timothy syndrome. Nature 2011, 471, 230-234.

(26) Paşca, S. P.; Portmann, T.; Voineagu, I.; Yazawa, M.; Shcheglovitov, A.; Paşca, A. M.; Cord, B.; Palmer, T. D.; Chikahisa, S.; Nishino, S.; Bernstein, J. A.; Hallmayer, J.; Geschwind, D. H.; Dolmetsch, R. E. Using iPSC-derived neurons to uncover cellular phenotypes associated with Timothy syndrome. Nat. Med. 2011, 17, $1657-1662$.

(27) Steinman, R. A.; Robinson, A. R.; Feghali-Bostwick, C. A. Antifibrotic effects of roscovitine in normal and scleroderma fibroblasts. PLoS One 2012, 7, No. e48560.

(28) Liu, N. A.; Jiang, H.; Ben-Shlomo, A.; Wawrowsky, K.; Fan, X. M.; Lin, S.; Melmed, S. Targeting zebrafish and murine pituitary corticotroph tumors with a cyclin-dependent kinase (CDK) inhibitor. Proc. Natl. Acad. Sci. U.S.A. 2011, 108, 8414-8419.

(29) Liu, N. A.; Araki, T.; Cuevas-Ramos, D.; Hong, J.; Ben-Shlomo, A.; Tone, Y.; Tone, M.; Melmed, S. Cyclin E - mediated human proopiomelanocortin regulation as a therapeutic target for Cushing disease. J. Clin. Endocrinol. Metab. 2015, 100, 2557-2564.

(30) Kitani, K.; Oguma, S.; Nishiki, T. I.; Ohmori, I.; Galons, H.; Matsui, H.; Meijer, L.; Tomizawa, K. A Cdk5 inhibitor enhances the induction of insulin secretion by exendin-4 both in vitro and in vivo. $J$. Physiol. Sci. 2007, 57, 235-239.
(31) Clinical Trials USA Treatment of Cushing's Disease with Rroscovitine, 2014. https://clinicaltrials.gov/ct2/show/NCT02160730 (accessed May 25, 2017).

(32) BioMed Central, UK Targeting the Rheumatoid Arthritis Synovial Fibroblast via Cyclin Dependent Kinase Inhibition - an Early Phase Trial (TRAFIC), 2014. https://www.isrctn.com/ ISRCTN36667085 (accessed May 25, 2017).

(33) Clinical Trials USA Evaluation of (R)-Roscovitine Safety and Effects in Subjects With Cystic Fibrosis, Homozygous for the F508delCFTR Mutation (ROSCO-CF), 2016. https://clinicaltrials.gov/ct2/ show/NCT02649751?term=roscovitine\&rank=1 (accessed May 25, 2017).

(34) Meijer, L.; Nelson, D.; Riazanski, V.; Gabdoulkhakova, A. G.; Hery-Arnaud, G.; Leberre, R.; Loaëc, N.; Oumata, N.; Galons, H.; Nowak, E.; Gueganton, L.; Dorothée, G.; Prochazkova, M.; Hall, B.; Kulkarni, A. B.; Gray, R. D.; Rossi, A. G.; Witko-Sarsat, V.; Norez, C.; Becq, F.; Ravel, D.; Mottier, D.; Rault, G. Modulating innate and adaptative immunity by (R)-roscovitine: potential therapeutic opportunity in cystic fibrosis. J. Innate Immun. 2016, 8, 330-49.

(35) Popowycz, F.; Fournet, G.; Schneider, C.; Bettayeb, K.; Ferandin, Y.; Lamigeon, C.; Tirado, O. M.; Mateo-Lozano, S.; Notario, V.; Colas, P.; Bernard, P.; Meijer, L.; Joseph, B. Pyrazolo[1,5a]-1,3,5-triazine as a purine bioisostere: access to potent $\mathrm{CDK}$ inhibitor $(R)$-roscovitine analogue. J. Med. Chem. 2009, 52, 655-663.

(36) Bettayeb, K.; Sallam, H. H.; Ferandin, Y.; Popowycz, F.; Fournet, G.; Hassan, M.; Echalier, A.; Bernard, P.; Endicott, J.; Joseph, B.; Meijer, L. N-\&-N, a new class of cell death-inducing, kinase inhibitors derived from the purine roscovitine. Mol. Cancer Ther. 2008, 7, 2713-2724.

(37) Bettayeb, K.; Baunbæk, D.; Delehouzé, C.; Loaëc, N.; Hole, A.; Baumli, S.; Endicott, J. A.; Douc-Rasy, S.; Bénard, J.; Oumata, N.; Galons, H.; Meijer, L. CDK inhibitors roscovitine and CR8 trigger Mcl-1 down-regulation and apoptotic cell death in neuroblastoma cell lines. Genes Cancer 2010, 1, 369-380.

(38) Barone, V.; Cossi, M. Quantum calculation of molecular energies and energy gradients in solution by a conductor solvent model. J. Phys. Chem. A 1998, 102, 1995-2001.

(39) Cossi, M.; Rega, N.; Scalmani, G.; Barone, V. Energies, structures, and electronic properties of molecules in solution with the C-PCM solvation model. J. Comput. Chem. 2003, 24, 669.

(40) Gresh, N.; Cisneros, A. G.; Darden, T. A.; Piquemal, J.-P. Anisotropic, Polarizable Molecular Mechanics Studies of Inter- and Intramolecular Interactions and Ligand-Macromolecule Complexes. A Bottom-Up Strategy. J. Chem. Theory Comput. 2007, 3, 1960-1986.

(41) Shi, Y.; Xia, Z.; Zhang, J.; Best, R.; Wu, C.; Ponder, J. W.; Ren, P. Y. Polarizable Atomic Multipole Based AMOEBA Force-Field for Proteins. J. Chem. Theory Comput. 2013, 9, 4046-4063.

(42) Grimme, S.; Antony, J.; Ehrlich, S.; Krieg, H. A Consistent and Accurate Ab Initio Parametrization of Density Functional Dispersion Correction (DFT-D) for the 94 Elements H-Pu. J. Chem. Phys. 2010, 132, No. 154104.

(43) Dunning, T. H. Gaussian Basis Sets for Use in Correlated Molecular Calculations. I. The atoms boron through neon and hydrogen. J. Chem. Phys. 1989, 90, 1007-1023.

(44) Feller, D. The Role of Data Bases in Support of Computational Chemistry Calculations. J. Comput. Chem. 1996, 17, 1571-1586.

(45) Frisch, M. J.; Trucks, G. W.; Schlegel, H. B.; Scuseria, G. E.; Robb, M. A.; Cheeseman, J. R.; Scalmani, G.; Barone, V.; Petersson, G. A.; Nakatsuji, H.; Li, X.; Caricato, M.; Marenich, A.; Bloino, J.; Janesko, B. G.; Gomperts, R.; Mennucci, B.; Hratchian, H. P.; Ortiz, J. V.; Izmaylov, A. F.; Sonnenberg, J. L.; Williams-Young, D.; Ding, F.; Lipparini, F.; Egidi, F.; Goings, J.; Peng, B.; Petrone, A.; Henderson, T.; Ranasinghe, D.; Zakrzewski, V. G.; Gao, J.; Rega, N.; Zheng, G.; Liang, W.; Hada, M.; Ehara, M.; Toyota, K.; Fukuda, R.; Hasegawa, J.; Ishida, M.; Nakajima, T.; Honda, Y.; Kitao, O.; Nakai, H.; Vreven, T.; Throssell, K.; Montgomery, J. A., Jr.; Peralta, J. E.; Ogliaro, F.; Bearpark, M.; Heyd, J. J.; Brothers, E.; Kudin, K. N.; Staroverov, V. N.; Keith, T.; Kobayashi, R.; Normand, J.; Raghavachari, K.; Rendell, A.; Burant, J. C.; Iyengar, S. S.; Tomasi, J.; Cossi, M.; Millam, J. M.; Klene, 
M.; Adamo, C.; Cammi, R.; Ochterski, J. W.; Martin, R. L.; Morokuma, K.; Farkas, O.; Foresman, J. B.; Fox, D. J. Gaussian 09, revision D.01; Gaussian, Inc.: Wallingford, CT, 2016.

(46) Becke, A. D.; Edgecombe, K. E. A simple measure of electron localization in atomic and molecular systems. J. Chem. Phys. 1990, 92, 5397-5403.

(47) Silvi, B.; Savin, A. Classification of chemical bonds based on topological analysis of electron localization functions. Nature 1994, 371, 683-686.

(48) Piquemal, J.-P.; Pilmé, J.; Parisel, O.; Gérard, H.; Fourré, I.; Bergès, J.; Gourlaouen, C.; De La Lande, A.; Van Severen, M. C.; Silvi, B. What can be learnt on biological or biomimetic systems with the topological analysis of the electron localization function ? Int. J. Quantum Chem. 2008, 108, 1951.

(49) Johnson, E. R.; Keinan, S.; Mori-Sanchez, P.; Contreras-Garcia, J.; Cohen, A. J.; Yang, W. Revealing non-covalent interactions. J. Am. Chem. Soc. 2010, 132, 6498-6506.

(50) Contreras-García, J.; Johnson, E. R.; Keinan, S.; Chaudret, R.; Piquemal, J.-P.; Beratan, D. N.; Yang, W. NCIPLOT: a program for plotting non-covalent interaction regions. J. Chem. Theory Comput. 2011, 7, 625-632.

(51) Nekardová, M.; Vymětalová, L.; Khirsariya, P.; Kováčová, S.; Hylsová, M.; Jorda, R.; Kryštof, V.; Fanfrlík, J.; Hobza, P.; Paruch, K. Structural basis of the interaction of cyclin-dependent kanase 2 with roscovitine and its analogues having bioisoteric central heterocycles. ChemPhysChem 2017, 18, 785.

(52) Jorda, R.; Paruch, K.; Krystof, V. Cyclin-dependent kinase inhibitors inspired by roscovitine: purine bioisosteres. Curr. Pharm. Des. 2012, 18, 2974-2980.

(53) El Hage, K.; Piquemal, J.-P.; Hobaika, Z.; Maroun, R. G.; Gresh, $\mathrm{N}$. Substituent-modulated affinities of halobenzene derivatives to the HIV-1 Integrase recognition site. Analyses of the interaction energies by parallel quantum chemical and polarizable molecular mechanics. $J$. Chem. Phys. A 2014, 118, 9772-9782. 